\title{
Peran Self Monitoring sebagai Mediator antara Job Characteristics dan Well-Being pada Guru Sekolah Inklusi
}

\section{The Role of Self Monitoring as a Mediator Between Job Characteristics and Well-Being in Inclusion School Teachers}

\author{
Ulifa Rahma, Zahratul Fauza, Faizah, Yuliezar Perwira Dara \\ Program Studi Psikologi Universitas Brawijaya, Malang, Indonesia
}

\begin{abstract}
This study aims to determine the role of teacher self-monitoring as a mediator between job characteristics (emotional job demands and trust in colleagues) and teacher well-being teachers in inclusive schools. The sample of this study was 204 teachers in Indonesia from elementary to high school levels in inclusive schools using $\mathrm{G}^{*}$ power. The sample selection technique in this study was accidental sampling teachers in Indonesia from elementary to high school levels in inclusive schools. The research method used is correlational quantitative research. This study uses four measuring instruments, namely the teacher well being scale, the self-monitoring scale, and, to measure job characteristics, the omnibus trust and the emotional job demand scales. Analysis of research data refers to Baron \& Kenny using process modeling analysis version 3.0 by Andrew Hayes. As a result, self monitoring is able to become a mediator between emotional job demand and teacher well-being. Self monitoring has also proven to be a mediator between trust in colleagues and teacher well-being.
\end{abstract}

Keywords: Job characterstics, self monitoring, well-being, teacher, inclusive school

\begin{abstract}
Abstrak: Penelitian ini bertujuan mengetahui peran teacher self monitoring sebagai mediator antara job characteristic (emotional job demands dan trust in colleagues) dan teacher well-being guru disekolah inklusi. Sampel dalam penelitian 204 guru dari jenjang Pendidikan Sekolah Dasar sampai dengan Sekolah Menengah Atas di sekolah inklusi menggunakan aplikasi G*power. Teknik pemilihan sampel dalam penelitian ini adalah accidental sampling yaitu seluruh guru inkusi yang ditemui dari jenjang Sekolah Dasar sampai Menengah Atas. Metode penelitian yang digunakan adalah penelitian kuantitatif korelasional. Penelitian ini menggunakan empat alat ukur, yaitu skala teacher well being, self monitoring dan, untuk mengukur job characteristics, skala omnibus trust dan emotional job demand. Analisis data penelitian mengacu pada Baron \& Kenny menggunakan analisis process modeling versi 3.0 oleh Andrew Hayes. Hasilnya self monitoring mampu menjadi mediator antara emotional job demand dan teacher well-being. Self monitoring juga terbukti mampu menjadi mediator antara trust in colleagues dan teacher well-being
\end{abstract}

Kata Kunci: Job characterstics, self monitoring, well-being, guru, sekolah inklusi

Penerapan pendidikan inklusi merupakan hal yang relatif baru sehingga akan menghadapi berbagai permasalahan dalam pelaksanaannya salah satunya oleh guru. Guru merupakan salah satu faktor yang menentukan keberhasilan dalam suatu upa-

Korespondensi tentang artikel ini dapat dapat dialamatkan kepada Ulifa Rahma melalui e-mail: ulifa.rahma@ub.ac.id 
ya pendidikan (Shabir, 2015). Guru menjadi salah satu faktor terpenting yang berkontribusi dalam prestasi belajar, kepuasan serta keberhasilan para siswa di sekolah (McCallum, Price, Graham, \& Morrison, 2017). Salah satu permasalahan yang dialami oleh guru di sekolah inklusi adalah kondisi kesejahteraan (well-being) guru yang rendah. Para guru melaporkan menghadapi berbagai tantangan dalam memenuhi kebutuhan semua anak di lingkungan inklusif termasuk lebih sedikit waktu yang tersedia untuk seluruh kelas, perilaku menantang dari siswa, tanggung jawab untuk hasil pendidikan dari siswa dengan beragam kebutuhan belajar, dan beban kerja yang meningkat (Forlin \& Chambers, 2011).

Fenomena mengenai permasalahan well-being guru inklusi adalah sering merasa kesulitan mengelola emosi positif dan tertekan menghadapi siswa berkebutuhan khusus, adanya perubahan kurikulum yang disesuaikan dan implementasinya masih belum dapat dilakukan dengan optimal dalam mendidik anak berkebutuhan khusus dan beban mengajar dipersepsikan lebih berat dibandingkan mengajar siswa reguler. Masalah lain yang dihadapi para guru di sekolah inklusi adalah perilaku siswa yang tidak sesuai, motivasi siswa dalam belajar, kedisiplinan, beban kerja guru yang reltif berat, tekanan dari segi waktu, konflik dengan staf sekolah dan kririk dari wali siswa. Guru merasakan tuntutan dan tekanan yang lebih besar ketika mengajar sekolah inklusi. Terutama karena pemahaman yang dimiliki guru tidak sesuai dengan pelaksanaan ketrampilan mendidik siswa berkebutuhan khusus (Rahmawati, Nashori, \& Rachmahana, 2020).

Tinjauan atas penelitian yang dilakukan antara tahun 1979 dan 2013 menemukan bahwa guru yang mengajar anak berkebutuhan khusus juga mengalami burnout, konflik peran, ambiguitas peran, dan kurangnya dukungan administratif sekolah (Brunsting, Sreckovic, \& Lane, 2014). Halhal diatas salah satunya dapat berpengaruh terhadap rendahnya well-being pada guru atau disebut teacher well-being (Skaalvik \& Skaalvik, 2010; Xanthopoulou, Bakker, Demerouti, \& Schaueli, 2007).

Salah satu strategi dalam meningkatkan teacher well-being adalah pengaturan pada job characteristics (Yin, Huang, \& Wang, 2016). de Jonge et al. (2001) dan Hakanen, Bakker dan Schaufeli (2006) menyatakan bahwa job characteristics menjadi prediktor yang penting dan memiliki dampak mendalam bagi teacher wellbeing. Job characteristics merupakan prediktor penting dari well-being, karena intervensi di tempat kerja yang dapat mengurangi atau menstabilkan tuntutan pekerjaan menjadi titik awal meningkatnya wellbeing (Jonge, Dorman, Janssen, Dollard, Landeweerd, \& Nijhuis, 2001).

Bakker dan Demerouti (2007) membagi job characteristic menjadi dua kategori yakni job demands dan job resource. Pada konteks profesi guru di sekolah, job demands disebut emotional job demands dan job resources disebut trust in colleagues (Yin, Huang, \& Lv, 2018). Emotional job demand sebagai salah satu kategori dari job characteristics didefinisikan sebagai tuntutan yang dipaksakan oleh frekuensi, intensitas dan interaksi dari pekerjaan (Brutheridge \& Lee, 2002). Menurut Yin (2015) Emotional job demands tidak hanya tenang dan selalu bersikap positif sepanjang hari, tetapi juga bagaimana seorang guru mengekspresikan dirinya, memperhatikan dan merawat siswanya serta membangun hubungan yang sehat antar guru dan siswa. Yin, Huang dan Wang (2016) juga menyatakan bahwa emotional job demand seorang guru secara positif berkaitan dengan kelelahan emosional guru sehingga hal tersebut berdampak pada kecemasan seorang guru. Emotional job demand yang tinggi dapat mengurangi kepuasan kerja dan hal ini dapat memengaruhi kesejahteraan individu. Bagi seorang guru emotional job demand berasal dari perilaku siswanya, beban kerja yang berlebihan dan lingkungan kerja yang ti- 
dak menguntungkan (Huang, Yin \& Lv 2019).

Trust in colleagues sebagai kategori lain dari job characteristics didefinsikan sebagai kepercayaan seorang guru kepada rekan kerjanya bahwa pihak rekan kerja bersifat baik, jujur, terbuka, kompeten, jujur dan dapat diandalkan (TschannenMoran \& Hoy, 2000). Persepsi guru tentang trust in colleagues dapat secara signifikan meningkatkan penerimaan mereka terhadap reformasi kurikulum dan persepsi hasil reformasi (Yin, Lee, dan Jin 2011). Kepercayaan pada rekan kerja memiliki peran positif dalam meningkatkan kemanjuran dan komitmen kolektif guru kepada siswa (Lee, Zhang, dan Yin 2011). Van Maele \& Van Houtte (2012) juga menemukan hubungan positif antara kepercayaan rekan kerja dan kepuasan guru dimana trust in colleagues dapat memotivasi guru untuk lebih terlibat dalam urusan sekolah serta menjaga kesehatan agar lebih baik melalui proses motivasi.

Meskipun hubungan antara well-being guru dengan job characteristics (emotional job demand dan trust in colleagues) dapat saling berkaitan, job characteristics belum dapat sepenuhnya menjelaskan perannya terhadap well-being guru (Yin et al., 2016). Faktor personal (personal factor) juga dapat dipertimbangkan sebagai mediasi atau penengah antar berbagai variabel tersebut (Schaufeli \& Taris, 2014; Bakker \& Demerouti, 2017). Karena, menurut Yin et al. (2018), dengan mengintegrasikan personal factor ke dalam job characteristics, maka akan terlihat prediktor tingkat situasi (sekolah) dan individu yang berperan penting dalam menjelaskan perbedaan dalam kesejahteraan guru. Dalam hal ini, salah satu personal factor yang dapat digunakan adalah self monitoring (Yin, Huang \& Wang, 2016).

Self monitoring didefinisikan sebagai individu yang mampu mengendalikan dan mengatur ekspresinya sesuai dengan situasi yang terjadi pada saat itu (Snyder, 1974). Self monitoring diperlukan oleh seorang individu agar individu tersebut dapat menunjukan performance yang sesuai dengan lingkungan di sekitarnya, termasuk dalam lingkurangn kerja (Baron \& Byrne, 1994). Seseorang dengan self monitoring yang tinggi cendrung akan bertindak sesuai dengan tuntutan situasional, individu tersebut akan menyembunyikan perasaan mereka yang sesungguhnya, seperti ekspresi wajah, suara dan postur tubuh (Erkutlu, 2012). Sedangkan seseorang dengan self monitoring yang rendah cenderung akan bertindak seperti yang mereka rasakan (Day, Shleicher, Unckless, \& Herner, 2000). Teacher self monitoring merupakan sebuah pelengkap yang dibutuhkan guru dalam keterampilan mengajar, namun hal tersebut juga dapat menyebabkan konflik dalam diri seseorang sehingga dapat mengurangi kesehatan psikologis (Huang et al., 2019). Guru sekolah dasar di Hongkong pada umumnya diminta untuk mengajar sebanyak 30 sesi per minggu, selain itu guru juga harus mengajar lebih dari satu mata pelajaran kepada siswa di kelas yang berbeda. Dari hal terebut guru mengalami interaksi dalam jumlah yang besar dengan siswa maupun kolega sehingga membutuhkan upaya yang besar pula dalam self monitoring, sehingga hal tersebut membuat well-being seorang guru dalam bahaya (Huang et al., 2019).

Dalam job characteristics terdapat kategori emotional job demands dan trust in colleagues yang memiliki hubungan berbeda dengan teacher self monitoring. Emotional job demands meningkatkan kesadaran guru bagaimana menampilkan pengaturan emosi dan mendorong guru untuk memikirkan bagaimana perilaku ditampilkan, sedangkan trust in colleagues dapat menciptakan lingkungan kerja yang mendukung yang memungkinkan guru untuk menjadi dirinya sendiri (Yin et al., 2017). Emotional job demands memiliki korelasi positif dengan self monitoring sedangkan trust in colleagues memiliki hubungan negatif dengan self monitoring (Huang, dkk 2019). Karena emotional job demand 
berkorelasi negatif dengan teacher wellbeing. Maka semakin tingginya emotional job demand yang diberikan kepada guru maka semakin ren-dah self monitoring mereka. Sedangkan semakin tinggi trust in colleagues guru makan semakin tinggi tingkat teacher self monitoring.

Personal factor dapat menjadi pertimbangan sebagai mediasi atau penengah dalam hubungan antara job characteristics (emotional job demands dan trust in colleagues) dengan teacher well-being, yang salah satunya adalah self monitoring (Schaufeli \& Taris 2014; Bakker \& Demerouti, 2017, Huang et al., 2019). Oleh karena itu, penelitian ini ingin menguji peran teacher self monitoring sebagai mediator antara job characteristics (yaitu, emotional job demands dan trust in colleagues) dengan teacher well-being pada guru sekolah Inklusi. Hipotesis dalam penelitian ini adalah:

1. Self monitoring berperan sebagai mediator antara job characteristics (emotional job) dan teacher well-being pada guru sekolah inklusi.

2. Self monitoring berperan sebagai mediator antara job characteristics (trust in colleagues) dan teacher wellbeing pada guru sekolah inklusi.

\section{Metode}

Penelitian ini menggunakan pendekatan kuantitatif, dengan jenis penelitian korelasional. Peneliti ingin menguji hubungan antara emotional job demand sebagai variabel independen (X1), trust in colleagues (X2) dengan teacher well-being sebagai variabel dependen (Y) dan self monitoring debagai variabel mediator (M).

\section{Sampel}

Sampel dalam penelitian ini adalah 204 guru Pendidikan inklusi dari seluruh level pendidikan (SD, SMP, SMA/SMK), baik dari sekolah negeri maupun sekolah swasta dan berusia $21-60$ tahun. Jumlah responden tersebut diperoleh berdasarkan hasil pengisian kuesioner secara online. Kuesioner memuat skala pengukuran penelitian tersebut disebarkan link-nya melalui media sosial kepada jaringan kenalan yang dimiliki oleh peneliti dengan permohonan bantuan untuk terus menye-barkan link tersebut ke jaringan yang mereka miliki. Berikut deskripsi data responden berdasarkan asal daerahnya.

Tabel 1. Data asal daerah subjek

\begin{tabular}{lc}
\hline \multicolumn{1}{c}{ Asal daerah sekolah } & Jumlah \\
\hline Bali & 3 \\
Banten & 6 \\
Batam & 1 \\
Jakarta & 10 \\
Jambi & 4 \\
Jawa Timur & 71 \\
Jawa Barat & 28 \\
Jawa Tengah & 9 \\
Kalimantan Timur & 14 \\
Kalimantan Barat & 10 \\
Kalimantan Tengah & 12 \\
Kalimantan Selatan & 1 \\
NTB & 1 \\
NTT & 2 \\
Sulawesi Utara & 1 \\
Sulawesi Selatan & 5 \\
Sulawesi Tengah & 7 \\
Sumatera Selatan & 8 \\
Sunmatera Utara & 5 \\
Riau & 5 \\
\hline
\end{tabular}

\section{Instrumen Penelitian}

Instrumen penelitian yang digunakan untuk mengukur teacher well-being adalah transadaptasi Teacher Well-Being Scale (TWBS) milik Collie, Shapka, Perry dan Andrew (2015). Dalam Teacher Well Being Scale (TWBS) terdapat 16 item yang terbagi dalam 3 faktor yaitu, banyaknya beban kerja yang diberikan kepada guru, berkaitan dengan sekolah sebagi organisasi, dan berkaitan dengan bagaimana interaksi siswa dan guru. Teacher well- 
being scale yang dikembangkan Collie et al. (2015) memiliki reliabilitas sebesar $(\alpha=0.87)$.

Untuk mengukur variabel emotional job demand pada guru, digunakan skala transadaptasi emotional labor item dari Yin (2015). Yin mengadaptasi skala emotional labor item milik Wong dan Law (2002) yang disesuaikan dengan konteks profesi guru. Skala emotional job demand yang dikembangkan oleh Yin (2015) memiliki reliabilitas sebesar $(\alpha=0.65)$. Selanjutnya, instrumen trust in colleagues menggunakan skala Omnibus Trust Scale dari Tschannen-Moran dan Hoy (2000). Peneliti menggunakan salah satu subtes pada penelitian ini yaitu trust in colleagues dengan nilai reliabilitasnya adalah 0.97. Untuk mengukur self monitoring peneliti melakukan transadaptasi skala Snyder dan Gangestad (1986) yang memiliki nilai reliabilitas sebesar $(\alpha=0.77)$

Peneliti melakukan pengujian alat ukur diskriminasi aitem, dari hasil data yang sudah diuji coba, aitem dalam skala teacher well-being, trust in colleagues, dan emotional job demand memiliki daya diskriminasi diatas cut off poin $\geq 0.20$. Sedangkan dari hasil data yang telah di uji coba pada skala self monitoring terdapat 6 aitem yang gugur. Untuk pengujian validitas, peneliti menggunakan face validity atau validitas tampang untuk mengetahui apakah kalimat yang digunakan pada skala penelitian sudah jelas, agar dapat mengetahui apakah skala sudah dapat menggambarkan variabel yang diukur di skala penelitian.

Validitas logis juga digunakan dalam penelitian ini oleh dosen yang memiliki keahlian berfokus pada bidang Pendidikan yang kompeten untuk menilai instrument penelitian ini. Expert judgement telah menilai dan menyatakan bahwa aitem dalam ketiga instrument penelitian layak digunakan serta sesuai guna menilai variabel yang akan diukur.

Uji reliabilitas dilakukan kembali di mana hasilnya menunjukkan skala teacher well-being memiliki reliabilitas sebesar 0,936, emotional job demand memiliki reliabilitas 0,726 , trust in colleagues bernilai reliabilitas 0.902 , dan self monitoring memiliki nilai reabilitas sebesar 0.720 .

Tabel 2. Hasil Uji Validitas Tampang

\begin{tabular}{|c|c|c|}
\hline $\begin{array}{l}\text { Validitas } \\
\text { Tampang }\end{array}$ & Jawaban & $\begin{array}{l}\text { Persen- } \\
\text { tase }\end{array}$ \\
\hline \multirow{5}{*}{$\begin{array}{l}\text { Kejelasan } \\
\text { kalimat dalam } \\
\text { kuesioner }\end{array}$} & Sangat Kurang & $0 \%$ \\
\hline & Kurang & $0 \%$ \\
\hline & Cukup & $34 \%$ \\
\hline & Baik & $52 \%$ \\
\hline & Sangat Baik & $14 \%$ \\
\hline \multirow{5}{*}{$\begin{array}{l}\text { Kesesuaian } \\
\text { kalimat dalam } \\
\text { kuesioner } \\
\text { dengan } \\
\text { kenyataan } \\
\text { kehidupan } \\
\text { sehari-hari } \\
\end{array}$} & Sangat Kurang & $0 \%$ \\
\hline & Kurang & $0 \%$ \\
\hline & Cukup & $22 \%$ \\
\hline & Baik & $54 \%$ \\
\hline & Sangat Baik & $24 \%$ \\
\hline \multirow{5}{*}{$\begin{array}{l}\text { Kejelasan } \\
\text { petunjuk } \\
\text { pengisian } \\
\text { dalam } \\
\text { kuesioner }\end{array}$} & Sangat Kurang & $0 \%$ \\
\hline & Kurang & $0 \%$ \\
\hline & Cukup & $18 \%$ \\
\hline & Baik & $51 \%$ \\
\hline & Sangat Baik & $31 \%$ \\
\hline \multirow{5}{*}{$\begin{array}{l}\text { Tampilan } \\
\text { kuesioner } \\
\text { secara } \\
\text { keseluruhan }\end{array}$} & Sangat Kurang & $0 \%$ \\
\hline & Kurang & $0 \%$ \\
\hline & Cukup & $24 \%$ \\
\hline & Baik & $45 \%$ \\
\hline & Sangat Baik & $31 \%$ \\
\hline \multirow{5}{*}{$\begin{array}{l}\text { kuesioner } \\
\text { memudahkan } \\
\text { dalam } \\
\text { menjawab }\end{array}$} & Sangat Kurang & $0 \%$ \\
\hline & Kurang & $0 \%$ \\
\hline & Cukup & $18 \%$ \\
\hline & Baik & $54 \%$ \\
\hline & Sangat Baik & $28 \%$ \\
\hline
\end{tabular}

\section{Analisis Data}

Sebelum dilakukan uji hipotesis, terlebih dahulu dilakukan uji asumsi, yaitu uji normalitas, linearitas dan heteroskedastisitas. Hasil uji normalitas semua variabel menghasilkan nilai signifikansi sebesar $0,000(p<0,05)$ sehingga dapat dikatakan terdistribusi secara tidak normal. Namun, dengan ukuran sampel yang cukup besar (>30) dalam penelitian ini, yaitu berjumlah 204 orang, ketidak normalan distribusi data $(<0,05)$ bukanlah masalah besar sehingga 
dapat diabaikan (Ghasemi, 2012). Hasil uji liniearitas menunjukkan bahwa variabel emotional job demand terhadap self monitoring memiliki nilai signifikansi 0.164 , trust in colleagues terhadap self monitoring sebesar 0.941, self monitoring terhadap teacher well-being sebesar 0.053, emotional job demand terhadap teacher well-being sebesar 0.235 , dan trust in colleagues terhadap teacher well-being sebesar 0.717. Berdasarkan data-data tersebut, semua variabel penelitian dapat dikatakan linier karena telah memenuhi syarat signifikansi $>0.05$.

Uji heteroskedastisitas mengguna-kan uji Glejser menunjukkan nilai signifikansi emotional job demand terhadap self monitoring sebesar 1, trust in colleagues terhadap self monitoring 0.585 , self monitoring terhadap teacher well-being 0.063 , emotional job demand terhadap teacher well-being 0.889 , dan trust in colleagues terhadap teacher well-being sebesar 0.356. Berdasarkan data-data tersebut, semua variabel penelitian ini telah memenuhi syarat signifikansi $(p>0.05)$, sehingga tidak terjadi heteroskedastisitas.

Selanjutnya, uji hipotesis dilakukan dengan bantuan software IBM SPSS Statistic version 25.0. for Windows menggunakan analisis process version 3.0 oleh Andrew Hayes. Uji hipotesis dilakukan untuk mengetahui peran self monitoring sebagai mediator. Dalam model yang diajukan, emotional job demand merupakan variabel independen $(\mathrm{X})$, self monitoring merupakan variabel mediator $(\mathrm{M})$, dan teacher well-being merupakan variabel depen-den (Y). Berdasarkan teori Baron \& Kenny (1986), terdapat empat tahapan yang dilakukan untuk menguji pengaruh variabel mediator, yaitu:

\section{Uji Hipotesis 1}

1. Meregresikan variabel dependen $1 / \mathrm{X} 1$ (emotional job demand) dengan variabel mediator (self monitoring).

2. Meregresikan variabel mediator ( self monitoring) dengan variabel independen (teacher well-beng).

3. Meregresikan variabel dependen (emotional job demand) dengan variabel independen (teacher well-being)

4. Meregresikan variabel dependen (emotional job demand), variabel mediator (self monitoring), dan variabel independen (teacher well-being).

\section{Uji Hipotesis 2}

1. Meregresikan variabel dependen $2 / \mathrm{X} 2$ (trust in colleagues) dengan variabel mediator (self monitoring).

2. Meregresikan variabel mediator (self monitoring) dengan variabel independen (teacher well-beng).

3. Meregresikan variabel dependen $2 / \mathrm{X} 2$ (trust in colleagues) dengan variabel independen (teacher well-being)

4. Meregresikan variabel dependen 2/X2 (trust in colleagues), variabel mediator (self monitoring), dan variabel independen (teacher well-being).

Interpretasi hasil analisis data didasarkan pada: jika nilai koefisien regresi berkurang setelah mengontrol variabel mediator, maka peran variabel mediasi terbukti. Jika hasil regresi pada seluruh tahapan adalah signifikan ( $\mathrm{p}<.05)$, maka dapat dikatakan terjadi partial mediation pada model penelitian. Apabila nilai signifikansi $p$ yang awalnya berpengaruh signifikan ( $\mathrm{p}<$ 0.5 ), lalu pada jalur c' (variabel dependen terhadap variabel independen melalui mediator) ditemukan hasil yang tidak signifikan ( $\mathrm{p}>0.5$ ), maka dikatakan terjadi full mediation (Baron \& Kenny, 1986).

\section{Hasil}

\section{Hasil Uji Hipotesis 1}

Hasil pengujian hipotesis 1 sesuai pada Gambar 1 dan Tabel 3 menunjukkan hasil perhitungan pertama pada jalur a, diketahui bahwa nilai signifikansi emotional 


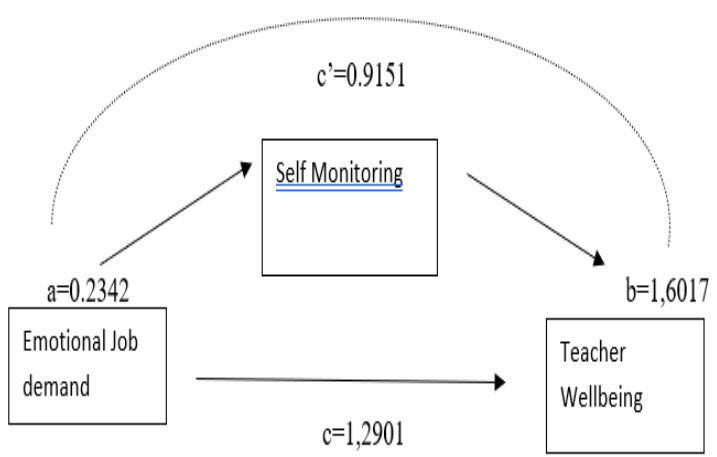

Gambar 1. Hasil Uji Hipotesis

job demand terhadap self monitoring adalah $0,0138(p<0,05)$. Artinya, terdapat hubungan yang signifikan antara kedua variabel tersebut. Nilai coefficient sebesar .2342 menunjukkan bahwa terdapat peran positif emotional job demand terhadap selfmonitoring. Hal ini juga menunjukkan bahwa dengan ada penambahan satuan unit emotional job demand, maka akan terjadi peningkatan sebesar .2342 pada variabel self monitoring. Koefisien regresi $\left(\mathrm{R}^{2}\right)$ sebesar 0297 menunjukkan bahwa variabel emotional job demand memiliki peran sebesar $2.97 \%$ terhadap self monitoring, sementara sisanya dipengaruhi oleh variabel eksternal.
Pada jalur b, diketahui bahwa nilai signifikansi self monitoring dengan teacher well-being adalah $0,000(p<0,05)$. Artinya, terdapat hubungan yang signifikan antara kedua variabel tersebut. Nilai koefesien yang didapatkan sebesar 1,6017 yang menunjukkan bahwa terdapat peran positif self monitoring terhadap teacher wellbeing. Hal ini juga menunjukkan bahwa dengan penambahan satuan unit emotional job demand, maka akan terjadi peningkatan sebesar .2342 pada variabel teacher well-being.

Berdasarkan hasil perhitungan ketiga, menggunakan analisis metode process seperti terlihat pada Tabel 3, diketahui berdasarkan coefficient determinasi $\left(\mathrm{R}^{2}\right)$, bahwa variable emotional job demand memiliki peran .2500 atau sebesar $25 \%$ terhadap self monitoring dan teacher wellbeing, sementara sisanya dipengaruhi oleh variabel lain yang tidak diteliti dalam penelitian ini.

Berdasarkan hasil perhitungan jalur c, diketahui bahwa nilai signifikansi dari emotional job demand terhadap teacher well-being adalah $0,0002(\mathrm{p}<0,05)$, artinya terdapat hubungan yag signifikan antara kedua variabel tersebut. Nilai koefisien yang didapatkan sebesar 1,2901.

Tabel 3. Hasil Uji Hipotesis

\begin{tabular}{|c|c|c|c|c|c|c|c|}
\hline \multirow{3}{*}{ Antecedent } & \multicolumn{7}{|c|}{ Consequent } \\
\hline & & \multicolumn{3}{|c|}{ M (Self monitoring) } & \multicolumn{3}{|c|}{ Y (Teacher Well-Being) } \\
\hline & & Coeff & $S E$ & $P$ & Coeff & $S E$ & $p$ \\
\hline $\begin{array}{l}X 1 \\
\text { (Emotional } \\
\text { Job Demand) }\end{array}$ & $a$ & 0,2342 & 0,0942 & $0,0138 c^{\prime}$ & 0,9151 & 0,3104 & 0,036 \\
\hline $\begin{array}{l}\mathrm{M} \text { (Self } \\
\text { monitoring) }\end{array}$ & - & - & - & $b$ & 1.6017 & 0,2283 & 0,000 \\
\hline \multirow[t]{2}{*}{ constant } & Im & 5,4311 & 1,6325 & $0,0010 I y$ & 66,4105 & 5,4409 & 0,0000 \\
\hline & & \multicolumn{3}{|c|}{$R^{2}=0,0297(p=0,0138)$} & \multicolumn{3}{|c|}{$R^{2}=0,2500(p=0,000)$} \\
\hline
\end{tabular}


Selanjutnya, hasil analisis mediasi pada jalur c', diketahui bahwa terdapat hubungan langsung emotional job demand terhadap teacher well-being melalui selfmonitoring dengan nilai signifikansi 0,036 $(p<0,05)$.

Hasil dari analisis bootstrapping Hayes (process) melalui software SPSS version 26 for windows diatas menyatakan bahwa antar variabel dalam penelitian ini memiliki peran yang negatif dan positif. Variabel emotional job demand memiliki peran positif terhadap variabel self monitoring (jalur a dapat terbukti). Yang berarti setiap terjadi peningkatan pada variabel emotional job demand maka akan terjadi peningkatan pula pada variabel self monitoring. Selanjutnya, variabel self monitoring memiliki peran positif terhadap teacher well-being yang berarti setiap terjadi peningkatan pada variabel self monitoring akan terjadi peningkatan pula pada variabel teacher wellbeing (jalur b terbukti). Selanjutnya, variabel emotional job demand memiliki peran positif terhadap teacher well-being (jalur c) sehingga terdapat pengaruh langsung. Jalur c' yang menggunakan analisis process karena melibatkan tiga variabel yaitu emotional job demand dan teacher wellbeing yang dapat dimediatori oleh self monitoring. Pengaruh langsung emotional job demand terhadap teacher well-being dapat dilihat dari nilai koefisien regresi jalur c yakni 1.2901 dan pengaruh tidak langsungnya dapat dilihat dari nilai koefisien jalur c' yakni 0.9151. Hal ini menunjukkan bahwa pengaruh langsung emotional job demand terhadap teacher well-being menjadi lebih kecil setelah dikontrol self monitoring $\left(c^{\prime}<c\right)$, dengan ini maka jalur c' dapat terbukti memiliki peran positif yang signifikan. Berdasarkan Baron dan Kenny (1986), peneliti dapat mengambil kesimpulan bahwa hasil analisis ini menunjukkan terjadi partial mediation dimana variabel independen mampu memengaruhi secara langsung variabel dependen tanpa melibatkan mediator.

\section{Uji Hipotesis 2}

Hasil pengujian hipotesis 2 sesuai pada Gambar 2 dan Tabel 4 menunjukkan bahwa perhitungan pertama pada jalur a, diketahui bahwa nilai signifikansi trust in colleagues terhadap self-monitoring adalah $0,0493(p<0,05)$. Artinya, terdapat hubungan yang signifikan antara kedua variabel tersebut. Nilai coefficient sebesar .0714 menunjukkan bahwa terdapat peran positif

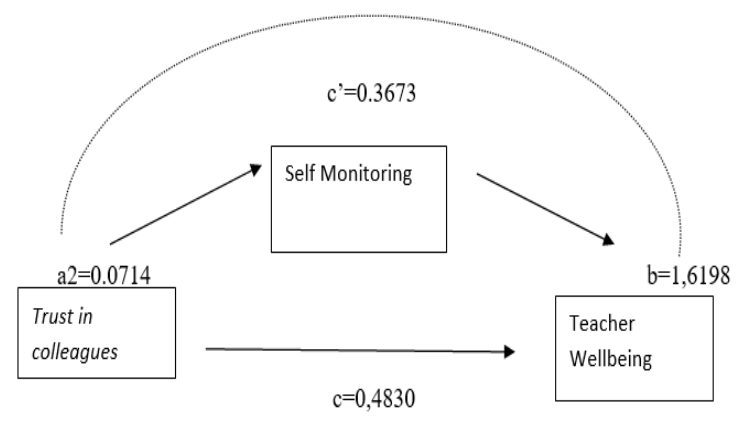

Gambar 2. Hasil Uji Hipotesis

Tabel 4. Hasil Uji Hipotesis

\begin{tabular}{|c|c|c|c|c|c|c|c|c|}
\hline \multirow{3}{*}{ Antecedent } & \multicolumn{8}{|c|}{ Consequent } \\
\hline & \multicolumn{4}{|c|}{$\mathrm{M}$ (Self monitoring) } & \multicolumn{4}{|c|}{ Y (Teacher Well-Being) } \\
\hline & & coeff & $S E$ & $P$ & & coeff & $S E$ & $p$ \\
\hline $\begin{array}{l}X 2 \text { (Trust in } \\
\text { colleagues) }\end{array}$ & $a$ & 0,0714 & 0,0361 & 0,0493 & $c^{\prime}$ & 0.3673 &, 1173 & 0,0020 \\
\hline $\begin{array}{c}\mathrm{M} \text { (Self } \\
\text { monitoring) }\end{array}$ & & - & - & - & $b$ & 1,6198 & 0,2265 & 0,0000 \\
\hline \multirow[t]{2}{*}{ constant } & Im & 6,8883 & 1,3144 & 0,0000 & Iy & 68,3428 & 5,5179 & 0,0000 \\
\hline & \multicolumn{4}{|c|}{$R^{2}=0,0190(p=0,0493)$} & \multicolumn{4}{|c|}{$R^{2}=0,2540(p=0,000)$} \\
\hline
\end{tabular}


trust in colleagues terhadap self monitoring. Hal ini juga menunjukkan bahwa dengan penambahan satuan unit trust in colleagues, maka akan terjadi peningkatan sebesar .0714 pada self monitoring. Koefisien regresi $\left(\mathrm{R}^{2}\right)$ sebesar .0190 menunjukkan bahwa variabel trust in colleagues memiliki peran sebesar $1.90 \%$ terhadap self-monitoring, sementara sisanya dipengaruhi oleh variabel eksternal.

Pada jalur $b$, diketahui bahwa nilai signifikansi self monitoring dengan teacher well-being adalah $0,000(p<0,05)$. Artinya, terdapat hubungan yang signifikan antara kedua variabel tersebut. Nilai koefesien yang didapatkan sebesar 1,6198 yang menunjukkan bahwa terdapat peran positif self-monitoring terhadap teacher wellbeing. Hal ini juga menunjukkan bahwa dengan penambahan satuan unit self monitoring, maka akan terjadi peningkatan 1.6198 pada variabel teacher well-being.

Berdasarkan hasil perhitungan ketiga menggunakan analisis metode process seperti terlihat pada tabel 4, diketahui bahwa berdasarkan skor coefficient deter-minasi $\left(\mathrm{R}^{2}\right)$, variabel trust in colleagues memiliki peran .254 atau sebesar $25,4 \%$ terhadap self monitoring dan teacher well-being, sementara sisanya dipengaruhi oleh variabel lain yang tidak diteliti dalam penelitian ini.

Berdasarkan hasil perhitungan jalur c, diketahui bahwa nilai signifikansi trust in colleagues terhadap teacher well-being adalah $0,0003(\mathrm{p}<0,05)$, artinya terdapat hubungan yag signifikan antara kedua variabel tersebut. Nilai koefisien yang didapatkan sebesar 1,2901. Selanjutnya, hasil analisis mediasi pada jalur c', diketa-hui bahwa terdapat hubungan langsung trust in colleagues terhadap teacher well-being melalui self-monitoring dengan nilai signifikansi 0,002 $(p<0,05)$.

Hasil dari analisis bootstrapping Hayes (process) melalui software SPSS version 26 for windows di atas menyatakan bahwa antar variabel dalam penelitian ini memiliki peran negatif dan positif. Varia- bel trust in colleagues memiliki peran yang positif terhadap variabel self monitoring (jalur a dapat terbukti). Hal ini berarti setiap terjadi peningkatan pada variabel trust in colleagues maka akan terjadi peningkatan pula pada variabel self monitoring. Selanjutnya, variabel self monitoring memiliki peran positif terhadap teacher wellbeing yang berarti setiap terjadi peningkatan pada variabel self monitoring akan terjadi peningkatan pula pada variabel teacher well-being (jalur $\mathrm{b}$ terbukti). Selanjutnya variabel trust in colleagues memiliki peran positif terhadap teacher well-being (jalur c) sehingga terdapat pengaruh langsung. Jalur c' yang menggunakan analisis process karena melibatkan tiga variabel yaitu trust in colleagues dan teacher wellbeing yang dapat dimediatori oleh self monitoring. Pengaruh langsung trust in colleagues terhadap teacher well-being dapat dilihat dari nilai koefisien regresi jalur c yakni 0.4830 dan pengaruh tidak langsungnya dapat dilihat dari nilai koefisien jalur c' yakni 0.3673. Hal ini menunjukkan bahwa pengaruh langsung variabel trust in colleagues terhadap teacher well-being menjadi lebih kecil setelah dikontrol self monitoring $\left(\mathrm{c}^{\prime}<\mathrm{c}\right)$, dengan ini maka jalur c' dapat terbukti memiliki peran positif yang signifikan.

Berdasarkan saran Baron dan Kenny (1986), peneliti dapat mengambil kesimpulan bahwa hasil analisis ini menunjukan terjadi partial mediation dimana variabel independen mampu mempengaruhi secara langsungvariabel dependen tanpa melibatkan mediator.

\section{Pembahasan}

Penelitian ini memiliki tiga variabel, variabel independen job characteristics yang terdiri dari emotional job demand dan trust in colleagues, variabel moderator self monitoring dan variabel dependen teacher well-being. Penelitian ini bertujuan untuk melihat apakah terdapat peran dari job characteristics (emotional job demand dan 
trust in colleagues) terhadap teacher wellbeing yang dimediatori oleh self monitoring pada guru sekolah inklusi.

Uji hipotesis pertama yang dilakukan dalam penelitian ini memiliki empat jalur regresi. Hasil uji hipotesis jalur a1 menunjukkan terdapat peran emotional job demand terhadap self monitoring. Koefisien regresi $\left(\mathrm{R}^{2}\right)$ sebesar .0297 menunjukkan bahwa variabel emotional job demand memiliki peran sebesar $2.97 \%$ terhadap self monitoring. Hal ini sejalan dengan penelitian Huang et al. (2019) yang menyatakan bahwa emotional job demand berkorelasi positif dengan self monitoring dan merupakan prasyarat yang dapat memengaruhi self monitoring. Bagi guru sekolah inklusi, emotional job demand menuntut mereka tidak hanya tetap tenang dan positif sepanjang hari mengajar dan menghadapi permasalahan maupun untuk memfasilitasi manajemen kelas, tetapi juga memperhatikan dan merawat siswa yang membutuhkan untuk membangun hubungan guru dan siswa yang sehat (Yin, 2015). Terutama dalam menghadapi siswa berkebutuhan khusus yang ada di kelas, tuntutan emosional (emotional demand) dibutuhkan agar para guru memiliki kesabaran dalam menghadapi siswa di kelas (Wulan \& Apriliani, 2017). Semakin tinggi emotional job demand guru maka akan diikuti dengan tingginya self monitoring guru dimana guru cenderung bertindak sesuai dengan tuntutan situasional dan menyembunyikan perasaan batin mereka dengan memantau ekspresi wajah mereka, suara, dan postur tubuh (Erkutlu, 2012).

Meskipun tingkat umum self monitoring dapat bervariasi antar individu, kecenderungan individu untuk mengontrol dan mengatur ekspresinya dapat berubah sesuai kondisi lingkungan. Self monitoring mudah dilakukan dan penting pada situasi baru. Namun, dalam hal interaksi seharihari dengan orang yang sudah dikenal, self monitoring cenderung menurun. Untuk guru yang dituntut untuk dapat memiliki ketrampilan mengajar dan manajemen emosi perlu adanya emotional job demand yang tinggi, kontrol diri, dan regulasi emosi yang ekspresif (Peng et al., 2010).

Hasil uji hipotesis jalur b1 menunjukkan terdapat peran positif self monitoring terhadap teacher well being. Hasil dari uji hipotesis jalur b1 sesuai dengan penelitian yang dilakukan oleh Kalis, Vannest dan Parker (2007) yang menyatakan bahwa self monitoring berdampak positif dengan efektifitas mengajar di kelas, hal ini dapat meningkatkan strategi mengajar di kelas dengan sedikit alokasi waktu, sumber daya, dukungan dan keterampilan yang terbatas. Dalam penelitian ini individu merasakan kinerja akademik siswa meningkat dan konsisten, dari hal tersebut individu dapat menciptakan dan menerapkan strategi belajar yang efektif. Sebelum self monitoring diterapkan subjek merasa frustasi dan merasa ingin berhenti dari pekerjaannya, namun sekarang subjek merasa ingin terus mengajar dan tidak lagi berpikir untuk berhenti dari pekerjaannya. Hal ini berkaitaan dengan hasil penelitian Zaki (2018) yang menyatakan bahwa efektifitas guru adalah faktor terpenting yang dapat meningkatkan kesejahteraan psikologis guru agar berfungsi normal, dapat mengembangkan potensi mereka, berkerja secara produktif dan kreatif serta mampu membangun hubungan yang positif dengan orang lain.

Hasil uji hipotesis jalur c1 menyatakan peran positif emotional job demand terhadap teacher well-being. Hasil dari uji hipotesis jalur c1 sesuai dengan hasil penelitian yang diakukan oleh Yin et al. (2016) yang menyatakan bila hubungan emotional job demand terhadap teacher well-being saling berkaitan melalui efek tidak langsung reappraisal. Emotional job demand berkaitan dengan kepuasan mengajar sehingga hal tersebut memengaruhi kesejahteraan guru. Kesejahteraan guru erat kaitannya dengan kepuasan kerja, perasaan puas dan berhasil yang dirasakan guru dapat memenuhi tuntutan kompetensinya khususnya secara sosial dan emo- 
sional. Menurut McCallum, Price, Graham dan Morrison (2017) tuntutan pekerjaan yang tinggi dapat membuat siswa belajar semakin kompleks, sehingga guru merasa berkontribusi dalam perkembangan anakanak dan merasa membuat perubahan dalam kehidupan para siswanya. Penelitian Yin (2015) menjelaskan emotional job demand mencakup beberapa hal yaitu tuntutan kemampuan untuk bisa menjadi tetap tenang dan positif sepanjang hari dan mampu membangun hubungan yang sehat antara guru dengan siswa. Hal ini tentu saja dapat membantu guru dalam mencapai tujuan kerjanya serta mengurangi konsekuensi pada tuntutan pekerjaannya sehingga berpengaruh pada kesejahteraan mereka.

Hasil uji hipotesis jalur c1', menjelaskan bila self monitoring memiliki pengaruh yang signifikan dalam memediasi hubungan antara emotional job demand dengan teacher well-being. Hal ini sejalan dengan penelitian Huang, Yin dan Lv (2019) yang menyatakan bahwa emotional job demand memiliki peran terhadap self monitoring sehingga menjadi salah satu alasan self monitoring memiliki pengaruh signifikan dalam memediasi hubungan antara emotional job demand dengan teacher wellbeing. Emotional job demand juga sangat tergantung pada bagaimana seorang guru memahami tuntutan tersebut, dan dalam penelitiannya, guru lebih dituntut untuk tidak menganggap hal tersebut sebagai rintangan dalam mengajar sehingga mebutuhkan self monitoring yang lebih tinggi. Penelitian mereka juga menyimpukan bahwa emotional job demand yang tinggi lebih membutuhkan kontrol ekspresi yang tinggi agar sesuai dengan tuntutan situasional.

Pada para guru sekolah inklusi, self monitoring diperlukan dalam menghadapi siswa dengan berbagai karakteristik di kelas. Perlu bagi guru untuk mampu mengendalikan dan mengatur ekspresinya sesuai dengan situasi yang terjadi pada saat itu (Snyder, 1974). Self monitoring diperlukan oleh seorang individu agar individu tersebut dapat menunjukan performance yang sesuai dengan lingkungan di sekitarnya, termasuk dalam lingkurangn kerja. Agar bertindak sesuai dengan tuntutan situasional, individu tersebut akan menyembunyikan perasaan mereka yang sesungguhnya, seperti ekspresi wajah, suara dan postur tubuh (Erkutlu, 2012). Dengan adanya teacher self monitoring sebagai mediator antara emotional job demands dan teacher well-being, guru mampu mengendalikan dan mengatur ekspresinya sesuai dengan situasi yang terjadi pada saat itu (Snyder, 1974). Dalam hal ini, guru inklusi mengahadapi siswa regular maupun siswa berkebutuhan khusus dan beban kerja lainnya.

Dengan cara demikian, guru tidak hanya akan mampu menunjukkan emotional job demand dan mengelola emosi dengan baik serta bersikap positif sepanjang hari, tetapi juga dapat mengekspresikan dirinya, memperhatikan dan merawat siswanya serta membangun hubungan yang sehat antar guru dan siswa regular maupun siswa berkebutuhan khusus. Selain itu, guru sekolah inklusi akan dapat berhubungan dengan kolega dan murid, dan hal ini pada akhirnya dapat membuat guru mengalami well-being berupa pencapaian kepuasan, tujuan, dan perasaan bahagia yang dibangun melalui proses kolaborasi dengan para kolega dan siswa. Aelterman, Engels, Petegem dan Verhaeghe (2007) menyatakan bahwa kesejahteraan guru mencerminkan keadaan emosi positif dimana faktor lingkungan, kebutuhan pribadi, dan harapan seorang guru mendapatkan hasil yang seimbang.

Dalam job characteristics terdapat kategori emotional job demand dan trust in colleagues yang memiliki hubungan berbeda dengan self monitoring guru. Emotional job demands meningkatkan kesadaran guru tentang bagaimana menampilkan pengaturan emosi yang baik dan mendorong guru untuk memikirkan bagaimana perilaku ditampilkan, sedangkan trust in colleagues dapat menciptakan lingkungan kerja yang 
mendukung yang memungkinkan guru untuk menjadi dirinya sendiri (Wahlstrom \& Louis, 2008; Yin et al., 2017). Juga, emotional job demand memiliki hubungan yang positif dengan self monitoring sedangkan trust in colleagues memiliki hubungan negatif dengan self monitoring (Huang et al., 2019).

Pada uji hipotesis 2 Berdasarkan hasil perhitungan pertama pada jalur a, diketahui bahwa terdapat peran positif trust in colleagues terhadap self monitoring. Trust in colleagues memiliki peran sebesar $1.90 \%$ terhadap self monitoring, sementara sisanya dipengaruhi oleh variabel eksternal. Hal ini sejalan dengan yang dikemukakan oleh Kilduff, Mehra, Gioia, Dennis dan Borgatti (2017) bahwa individu yang memiliki self monitoring yang tinggi dapat membangun kepercayaan di antara rekanrekan mereka (trust in colleagues). Dengan tingginya trust in colleagues, guru dapat merasa lebih nyaman, menjadi otentik dan kebutuhan mereka untuk self monitoring menjadi berkurang. Dengan kata lain, faktor lingkungan dapat mengaktifkan atau membentuk self monitoring pada individu (Schaufeli \& Taris, 2014)

Pada jalur b, terdapat peran positif self monitoring terhadap teacher wellbeing. Trust in colleagues memiliki peran sebesar $25,4 \%$ terhadap self monitoring dan teacher well-being, sementara sisanya dipengaruhi oleh variabel lain yang tidak diteliti dalam penelitian ini (variabel eksternal). Selanjutnya berdasarkan hasil perhitungan jalur $\mathrm{c}$, terdapat hubungan positif yang signifikan antara trust in colleagues dengan teacher well-being. Hasil penelitian De Jonge, Dormann, Janssen, Dollard, Landeweerd dan Nijhuis, (2001) menunjukkan bahwa job characteristics, salah satunya trust in colleagues, merupakan prediktor penting yang memiliki dampak mendalam bagi well-being guru.

Selanjutnya, hasil analisis mediasi pada jalur c', diketahui bahwa terdapat hubungan langsung trust in colleagues terhadap teacher well-being melalui self monitoring. Hal ini didukung oleh Yin, Huang dan Wang (2016) yang menyatakan bahwa meskipun hubungan antara teacher well-being dengan trust in colleague saling berkaitan satu sama lain, namun trust in colleagues belum seutuhnya menjelaskan perannya terhadap teacher well-being. Lee, Zhang dan Yin (2019) mengatakan bahwa dalam hubungan antara teacher well-being dengan trust in colleagues dapat di mediasi oleh personal factor yaitu self monitoring (Yin, Huang, \& Wang, 2016). Kilduff et al. (2017) menjelaskan bahwa individu yang memiliki self monitoring mampu menyesuaikan sikap dan perilaku mereka dengan tuntutan situasi yang berbeda. Sebaliknya, individu yang memiliki self monitoring rendah cenderung jujur pada diri sendiri dalam hal konsistensi dalam sikap dan perilaku dalam berbagai situasi. Individu dengan self monitoring tinggi dapat membangun kepercayaan di antara rekan-rekan mereka (trust in colleagues), dimana mereka dapat menyesuaikan diri dalam berbagai situasi dan berusaha memastikan bahwa interaksi sosial yang dilakukan berhasil. Usaha ini melibatkan keaktifan dalam membantu orang lain dalam hal-hal yang berhubungan dengan pekerjaan. Misalnya cenderung berbicara lebih dulu, memotivasi orang lain dengan menetapkan tujuan yang jelas, menunjukkan bahwa upaya akan dihargai, mendorong orang lain untuk bekerja sama, mendukung, dan mendengarkan saran orang lain.

Sebaliknya, individu dengan self monitoring rendah cenderung menjadi diri mereka sendiri tanpa memandang situasi tersebut dan lebih memiliki minat terhadap diri mereka sendiri. Sehingga ketika individu mampu menunjukkan self monitoring maka ia memiliki trust in colleagues. Trust merupakan keyakinan individu atau kelompok yang mudah dipengaruhi oleh pihak lain bahwa pihak tersebut bersifat baik, dapat diandalkan, kompeten, jujur dan terbuka (Tschennen-Moran \& Hoy, 2000). Trust dapat memfasilitasi kolaborasi antara guru dan orang-orang di sekitar mereka 
yang dapat menyebabkan keberhasilan secara signifikan dan memediasi hubungan antara budaya belajar siswa dan kepuasan kerja guru (Van Houtte, 2006). Dalam analisis tersebut, terdapat tiga referensi trust salah satunya adalah trust in colleagues. Trust in colleagues merupakan kepercayaan seorang guru kepada rekan kerjanya bahwa pihak rekan kerja bersifat baik, jujur, terbuka, kompeten, jujur dan dapat diandalkan (Tschannen-Moran \& Hoy, 2000). Kepercayaan pada rekan kerja memiliki peran positif dalam meningkatkan kemanjuran dan komitmen kolektif guru kepada siswa (Lee, Zhang, dan Yin 2011). Trust in colleagues merupakan prediktor penting yang memiliki dampak mendalam bagi teacher well-being, karena dapat mengurangi atau menstabilkan tuntutan pekerjaan dalam mengintervensi di tempat kerja sehingga menjadi proses awal meningkatnya kesejahteraan karyawan (De Jonge, Dorman, Janssen, Dollard, Landeweerd \& Nijhuis, 2001).

Penelitian ini menemukan hasil bahwa self monitoring mampu menjadi me-diator antara job characteristics (emotional job demand dan trust in colleagues) dengan teacher well-being. Hal ini didukung oleh penelitian Schaufeli dan Taris (2014) serta Bakker dan Demerouti (2017) yang melaporkan bahwa self monitoring sebagai personal factor dapat menjadi mediasi atau penengah dalam hubungan antara job characteristics dengan teacher well being (Schaufeli \& Taris 2014; Bakker \& Demerouti, 2017).

\section{Simpulan}

Hasil analisis data yang dilakukan peneliti terhadap 204 guru inklusi sekolah formal di Indonesia menghasilkan kesimpulan bahwa self monitoring terbukti mampu menjadi mediator antara emotional job demand dan teacher well-being. Self monitoring juga terbukti mampu menjadi mediator antara trust in colleagues dan teacher well-being pada guru di sekolah inklusi. Guru inklusi dapat menerapkan self monitoring di kelasnya agar proses belajar mengajar dapat berjalan lebih efektif Ketika menghadapi siswa dengan berbagai karakteristiknya. Hal ini berperan dalam emotional job demand yang dimiliki guru inklusi yang menuntut guru untuk mampu mengelola emosi dalam menghadapi situasi kelas, membangun hubungan positif dengan siswa berkebutuhan khusus maupun regular yang berdampak pada kesejahteraan pada guru inklusi. Trust in colleagues juga membantu guru sekolah inklusi memfasilitasi kolaborasi antara guru dan orang-orang di sekitar mereka yang dapat menyebabkan keberhasilan dalam memediasi hubungan serta budaya belajar siswa, meningkatkan komitmen guru kepada siswa dan kesejahteraan guru sekolah inklusi.

\section{Saran}

Saran untuk peneliti selanjutnya adalah dapat meneliti variabel mediator lain, misalnya self efficacy, sebagai variabel faktor personal lainnya selain self monitoring. Peneliti lain juga dapat menggunakan metode penelitian kualitatif untuk mendapatkan data mendalam mengenai self monitoring, job characteristics dan well-being pada guru sekolah inklusi maupun pada guru secara umum. Penelitian ini diharapkan dapat menjadi bahan rekomendasi untuk pihak sekolah terkait kesejahteraan guru, sehingga pihak sekolah lebih memperhatikan lagi kesejahteraan guru di sekolah. Cara meningkatkan well-being guru sekolah inklusi dapat dilakukan salah satunya dengan meningkatkan perasaan puas dan berhasil dalam memenuhi tuntutan kompetensi yang dimiliki secara sosial dan emosional pada guru. Guru yang memiliki self monitoring, tidak hanya meningkatkan dirinya dalam mengaplikasikan proses belajar mengajar namun juga berdampak pada optimalisasi hasil siswa dalam proses pembelajaran. Kualitas self monitoring pada guru sekolah inklusi dapat 
dilakukan di antaranya dengan menentukan tujuan, membuat dan menerapkan rencana apa yang akan dilakukan, berfokus pada tugas (on-task), membuat pernyataan posi- tif kepada rekan, menyelesaikan pekerjaan, dan memenuhi apa yang menjadi tuntutan guru sekolah inklusi.

\section{Daftar Pustaka}

Aelterman, A., Engels, N., Van Petegem, K., \& Pierre Verhaeghe, J. (2007). The well-being of teachers in flanders: the importance of a supportive school culture. Educational Studies, 33(3), 285-297.

https://doi.org/10.1080/030556907014 23085

Bakker, A. B., \& Demerouti, E. (2017). The job demands-resources model: State of the art. Journal of Managerial Psychology, 22(3), 309-328. https://doi.org/10.1108/026839407107 33115

Baron, R. A., \& Byrne, D. (1994). Social psychology: understanding human interaction. Boston: Allyn and Bacon Inc.

Baron, R. M., \& Kenny, D. A. (1986). The moderator-mediator variable distinction in social psychological research: Conceptual, strategic, and statistical considerations. Journal of Personality and Social Psychology, 51(6), 1173-1182. https://doi.org/10.1037/00223514.51.6.1173

Brotheridge, C. M., \& Lee, R. T. (2002). Testing a conservation of resources model of the dynamics of emotional labor. Journal of Occupational Health Psychology, 7(1), 57-67. https://doi.org/10.1037/10768998.7.1.57

Brunsting, N. C., Sreckovic, M. A., \& Lane, K. L. (2014). Special education teacher burnout: A Synthesis of Research from 1979 to 2013. Education \& Treatment of Children,
37(4), 681-712. https://doi.org/10.1353/etc.2014.0032

Day, D. V., Schleicher, D. J., Unckless, A. L., \& Hiller, N. J. (2002). Selfmonitoring personality at work: A meta-analytic investigation of construct validity. Journal of Applied Psychology, 87(2), 390-401. https://doi.org/10.1037/00219010.87.2.390

De Jonge, J., Dormann, C., Janssen, P. P., Dollard, M. F., Landeweerd, J. A., \& Nijhuis, F. J. (2001). Testing reciprocal relationships between job characteristics and psychological well-being: A cross-lagged structural equation model. Journal of Occupational and Organizational Psychology, 74(1), 29-46. https://doi.org/10.1348/096317901167 217

Erkutlu, H. (2012). Impact of psychological hardiness and selfmonitoring on teacher burnout. Hacettepe Üniversitesi Ĕgitim Fakültesi Dergisi, 43(43), 186-197. Retrieved from http://www.efdergi.hacettepe.edu.tr/en glish/abstracts/43/pdf/HAKAN\%20E R KUTLU.pdf

Forlin, C., \& Chambers, D. (2011). Teacher preparation for inclusive education: increasing knowledge but raising concerns. Asia-Pacific Journal of Teacher Education, 39(1), 17-32. https://doi.org/10.1080/1359866x.201 0.540850

Ghasemi, A., \& Zahediasl, S. (2012). Normality tests for statistical analysis: 
a guide for non-stasticians. International Journal of Endocrinology and Metabolism, 10(2), 486-489.

https://doi.org/10.5812/ijem.3505

Hakanen, J. J., Bakker, A. B., \& Schaufeli, W. B. (2006). Burnout and work engagement among teachers. Journal of School Psychology, 43(6), 495-513. https://doi.org/10.1016/j.jsp.2005.11.0 01

Huang, S., Yin, H., \& Lv, L. (2019). Job characteristics and teacher well-being: the mediation of teacher selfmonitoring and teacher self-efficacy. Educational Psychology, 39(3), 313331.https://doi.org/10.1080/01443410. 2018.1543855

Kalis, T. M., Vannest, K. J., \& Parker, R. (2007). Praise counts: Using selfmonitoring to increase effective teaching practices. Preventing School Failure: Alternative Education for Children and Youth, 51(3), 20-27. https://doi.org/10.3200/PSFL.51.3.2027

Kilduff M., Mehra A., (Denny) Gioia D.A., Borgatti S. (2017) Brokering Trust to Enhance Leadership: A SelfMonitoring Approach to Leadership Emergence. In: Glückler J., Lazega E., Hammer I. (eds). Knowledge and Space, 11, 221-240. https://doi.org/10.1007/978-3-31945023-0_11

Lee, J. C. K., Zhang, Z., \& Yin, H. (2011). A multilevel analysis of the impact of a professional learning community, faculty trust in colleagues and collective efficacy on teacher commitment to students. Teaching and Teacher Education, 27(5), 820-830. https://doi.org/10.1016/j.tate.2011.01. 006

McCallum, F., Price, D., Graham, A. \& Morrison, A. (2017). Teacher wellbeing: a review of the literature. Australia: The University of Adelaide

Peng K. Z., Wong C. S., \& Che H. S. (2010). The missing link between emotional demands and exhaustion. Journal of Managerial Psychology, 25(7), 777-798.

https://doi.org/10.1108/026839410110 75300

Rahmawati, U. N., Nashori, F., Rachmahana, R. S. (2020). Pelatihan mindfulness teaching untuk meningkatkan kesejahteraan. Psympathic: Jurnal Ilmiah Psikologi, 7(1), 49-60. https://doi.org/10.15575/psy.v7i1.824 1

Schaufeli, W. B., \& Taris, T. W. (2014). A Critical Review of the Job DemandsResources Model: Implications for Improving Work and Health. Bridging Occupational, Organizational and Public Health: A Transdisciplinary Approach, 43-67. https://doi.org/10.1007/978-94-0075640-3

Shabir, U. M. (2015). Kedudukan guru sebagai pendidik. Journal UIN Alauddin, 221-232. http://journal.uinalauddin.ac.id/index.php/auladuna/arti cle/view/878

Skaalvik, E. M., \& Skaalvik, S. (2010). Teacher Self-Efficacy and Teacher Burnout: A Study of Relations. Teaching and Teacher Education, 26: 1059-1069. http://dx.doi.org/10.1016/j.tate.2009.1 1.001

Snyder, M. (1974). Self-monitoring of expressive behavior. Journal of personality and social psychology, 30(4), 526-537. https://doi.org/10.1037/h0037039

Tschannen-Moran, M., \& Hoy, W. K. (2000). A multidisciplinary analysis of the nature, meaning, and measurement 
of trust. Review of Educational Research, 70(4), 547-593. https://doi.org/10.3102/003465430700 04547

Van Houtte, M. (2006). Tracking and Teacher Satisfaction: Role of Study Culture and Trust. The Journal of Educational Research, 99(4),247-256. https://doi.org/10.3200/JOER.99.4.247 $-256$

Van Houtte, M. \& Van Maele, D. (2011), "The black box revelation: In search for conceptual clarity regarding climate and culture in school effectiveness research", Oxford Review of Education, 37(4), 505-524. Retrieved February 28, 2021, from http://www.jstor.org/stable/23047912

Wulan, D.K. \& Apriliani, A. C. (2017). Job Demands Dan Burnout Pada Guru Sekolah Luar Biasa (SLB) Negeri. Jurnal Penelitian dan Pengukuran Psikologi, 6(1), 17-25. https://doi.org/10.21009/JPPP.061.03

Xanthopoulou, D., Bakker, A. B., Demerouti, E., \& Schaufeli, W. B. (2007). The role of personal resources in the job demands-resources model. International Journal of Stress Management, 14(2), 121-141. https://doi.org/doi/10.1037/10725245.14.2.121

Yin, H. (2015). The effect of teachers' emotional labour on teaching satisfaction: Moderation of emotional intelligence. Teachers and Teaching, 21(7),

789-810. https://doi.org/10.1080/13540602.201 4.995482

Yin, H., Huang, S., \& Wang, W. (2016). Work environment characteristics and teacher well-being: The mediation of emotion regulation strategies. International Journal of Environmental Research and Public Health, 13(9), 907. https://doi.org/10.3390/ijerph1309090 7

Yin, H. B., Lee, J. C., \& Jin, Y. L. (2011). Teacher receptivity to curriculum reform and the need for trust: An exploratory study from Southwest China. The Asia-Pacific Education Researcher, 20(1), 35-47. http://ejournals.ph/form/cite.php?id=4 074

Yin, H., Huang, S., \& Lv, L. (2018). A Multilevel Analysis of Job Characteristics, Emotion Regulation and Teacher Well-Being: A Job Demands-Resources Model. Frontiers in $\quad 2395$. https://doi.org/10.3389/fpsyg.2018.02 395

Zaki, S. (2018). Enhancing teacher effectiveness through psychological well-being: a key to improve quality of teachers. International Journal of Research in Social Sciences, 8(7), 286-295. Retrieved from https://www.ijmra.us/project\%20doc/2 018/IJRSS_JULY2018/IJMRA14042.pdf 